\title{
Airway Injury During Emergency Transcutaneous Airway Access: A Comparison at Cricothyroid and Tracheal Sites
}

\author{
Nazar Salah, FCARSI \\ Ismat El Saigh, FRCA \\ Niamh Hayes, FCARSI
}

Conan McCaul, FFARCSI

BACKGROUND: Oxygenation via the cricothyroid membrane (CTM) may be required in emergencies, but inadvertent tracheal cannulation may occur. In this study, we compared airway injury between the tracheal and CTM sites using different techniques for airway access.

METHODS: Anesthesiologists performed 4 airway access techniques on excised porcine tracheas. The techniques were 1) wire-guided (WGT), 2) trocar (TT), 3) needle cannula (NCT), and 4) surgical-scalpel with endotracheal tube (ST). Participants performed each technique at both the CTM and tracheal sites. Specimens were assessed for injury.

RESULTS: Injury was observed in 8 of 40 and 27 of 40 specimens at the CTM and tracheal sites, respectively $(P<0.001)$. Injury was more frequent at the tracheal site compared with the CTM in both the TT and ST groups $(P=0.02)$ but not for the NCT and WGT. The rank order for any injury at the tracheal site was ST (9 of 10) = TT $(9$ of 10$)>$ WGT $(6$ of 10$)>\operatorname{NCT}(3$ of 10$)(P=0.02$, highest versus lowest), whereas there was no difference in injury at the CTM. The rank order for posterior injury at the tracheal site was TT $(9$ of 10$)=$ ST $(9$ of 10) $>$ WGT $(5$ of 10) $>$ NCT (2 of 10$)(P=0.005$, highest versus lowest). The rank order for penetrating injury at the tracheal site was ST $(6$ of 10$)=$ TT $(6$ of 10$)>$ WGT $(2$ of 10$)>$ NCT $(1$ of 10$)$ $(P=0.057$, highest versus lowest). There was no difference in the incidence of lateral, superficial, or perforating injuries among sites and techniques. Fractures were more common at the tracheal site (15 of 40 vs 0 of $40, P<0.001)$ and differed by technique. The rank order of fracture incidence at the tracheal site was ST (6 of $10)>$ WGT $(5$ of 10$)>$ TT $(4$ of 10$)>\operatorname{NCT}(0$ of 10$)(P=0.011$, highest to lowest $)$. Compression of $>50 \%$ was seen in 10 of 40 vs 28 of $40(P<0.001)$ specimens at the CTM and tracheal sites, respectively. The rank order of compression of $>50 \%$ of airway lumen for both sites was TT $>$ ST $>$ WGT $>$ NCT $(P=0.03, P<0.001$, CTM and tracheal sites, respectively, highest versus lowest).

CONCLUSION: Airway injury and luminal compression were more common at the tracheal site than at the CTM. The ST and TT were associated with the highest incidence of injury. This has implications for emergency airway access in cases in which it may be difficult to accurately identify the CTM.

(Anesth Analg 2009;109:1901-7)

$E$ performed only in dire clinical scenarios as the final step in a rescue algorithm. ${ }^{1}$ Saving time is critical to avoiding death or brain injury. Although the procedure is frequently successful when performed by experienced personnel, complications are common. ${ }^{2}$ Cricothyroid anatomy may be difficult to determine in patients who require emergency oxygenation, and this may result in inadvertent attempts to insert the airway

From the Department of Anaesthesia, Rotunda Hospital, Dublin,
Ireland.

Accepted for publication August 7, 2009.

Supported by internal funding.

Reprints will not be available from the author.

Address correspondence to Conan McCaul, FFARCSI, Department of Anaesthesia, Rotunda Hospital, Parnell Square, Dublin 2, Ireland. Address e-mail to cmccaul@rotunda.ie.

Copyright (C) 2009 International Anesthesia Research Society DOl: 10.1213/ANE.0b013e3181bdd1ba device away from the intended site, the cricothyroid membrane (CTM). In cadaveric studies, malpositioning through the trachea itself and even through the thyroid cartilage has been reported in addition to subcutaneous and paratracheal placements by emergency room and intensive care physicians. ${ }^{3-5}$ This malpositioning carries a risk of significant airway injury even if it enables emergency oxygenation in the acute setting. Even correct placement through the CTM has been associated with tracheal, mediastinal, and esophageal injury in the elective intensive care setting. ${ }^{6}$

We sought to determine the incidence and pattern of airway injury in an excised porcine airway model of percutaneous airway access for 4 different emergency airway access techniques at 2 different airway sites. To realistically reflect the clinical situation, in which some airway devices are anatomically incorrectly placed, we studied use of the airway devices both at the recommended site, i.e., the CTM, and at a more distant tracheal site. The patterns of injuries at these sites may 
be different for several reasons. First, the trachea presents continuous cartilage anteriorly, increasing the likelihood of fracture. Second, the trachea is not a circumferential structure, increasing the likelihood of compression and posterior injury. Third, the posterior wall consists of muscle and soft tissue, which offer less resistance to penetration. We hypothesized that the incidence of airway injuries would be more frequent at the tracheal site than at the CTM.

\section{METHODS}

Approval from the local research ethics committee was obtained for the study. Excised porcine tracheas with intact larynxes and CTMs were obtained from a local butcher. These specimens were chosen as the best anatomic approximation of the female adult airway, which has an average coronal diameter of $15.5 \mathrm{~mm} .7$

\section{Participants}

Participants were 10 anesthetic trainees who had previously trained on a manikin (Bill I, VBM Medizintechnik $\mathrm{GmbH}$, Tuttlingen, Germany) for the insertion of the 4 studied devices. Six trainees had 5 or fewer years of experience, 2 had 5-10 yr, and 2 had more than $10 \mathrm{yr}$ of experience. The trainees were not informed as to the purpose of the study so as not to affect their performance. The order of device insertion was randomized. One fresh trachea preparation was used for each device ( 2 insertions). Each specimen was used for 1 insertion at the cricothyroid and the tracheal site.

\section{Specimen Preparation}

The specimens were prepared as follows. Redundant surrounding tissue was excised, leaving the larynx, CTM, and trachea in anatomic continuity. The tracheas were cut distally to provide specimens of similar length. Synthetic skin from an anatomically correct airway manikin (Bill I, VBM Medizintechnik $\mathrm{GmbH}$ ) was applied over the trachea, which was mounted, using pins, on a 1-mm-thick white cardboard overlying a $45 \times 30 \mathrm{~cm}$ corkboard. Two insertion sites on the skin were marked: the proximal, over the CTM (cricothyroid site), and the distal, $3 \mathrm{~cm}$ caudal to the proximal marking (tracheal site). A web camera was placed in the distal tracheal lumen and oriented cephalad to capture video images during device insertion. The image was not visible to the participant. The purpose of the camera was to record compression of the trachea and to determine correct placement of the device in the tracheal lumen.

\section{Airway Techniques}

Four techniques were used in this study.

\section{Trocar Technique}

The trocar technique (TT) was performed with a Quicktrach II (VBM Medizintechnik GmbH), which consisted of a preassembled cuffed cricothyroidotomy

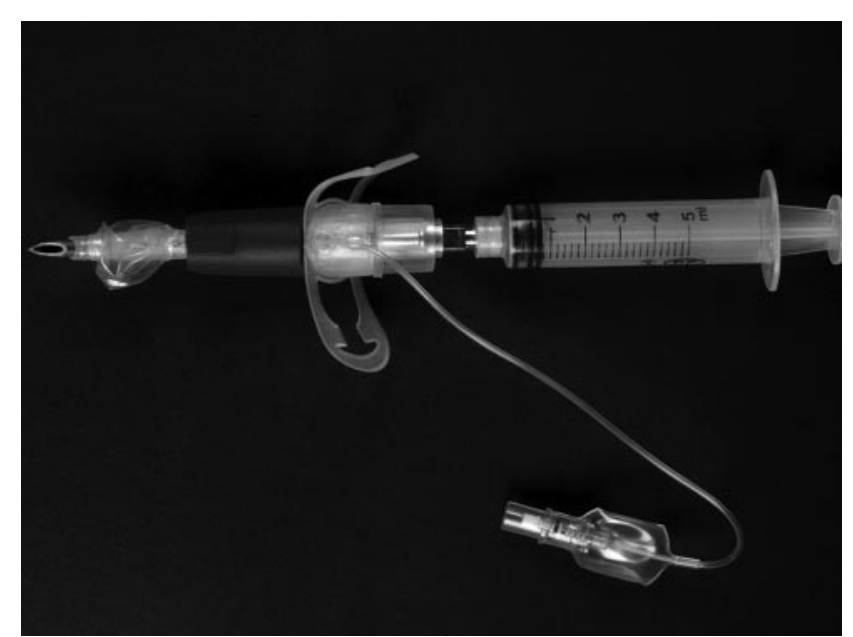

Figure 1. Trocar equipment: Quicktrach II (VBM Medizintechnik $\mathrm{GmbH}$ ).

tube, internal diameter $4 \mathrm{~mm}$ and external diameter $5.5-7.3 \mathrm{~mm}$ (Fig. 1). It is loaded over a slightly curved trocar, external diameter $4 \mathrm{~mm}$ with a $2-\mathrm{mm}$ cutting edge. A removable red rubber stopper fits around the outside of the tube distally; it acts as a safety mechanism to limit the posterior advance of the trocar toward the tracheal wall. Extension tubing is used to connect the tube to a standard $15-\mathrm{mm}$ port. The assembled device is advanced, with a 5 - $\mathrm{mL}$ syringe attached, through skin until puncture of the airway lumen occurs. Air is aspirated to confirm placement. The rubber stopper is removed and the trocar is withdrawn. The cuffed tube is advanced further into the airway lumen until the flanges make contact with the skin.

\section{Needle Cricothyroidotomy}

A 13-gauge cricothyroidotomy cannula, internal diameter $1.55 \mathrm{~mm}$ and external diameter $2.33 \mathrm{~mm}$, was used (VBM Medizintechnik $\mathrm{GmbH}$ ) with a 5-mL syringe attached (Fig. 2). The needle was advanced through skin and underlying tissues until puncture of the airway occurred. Air was aspirated to confirm placement. The cannula was then advanced over the needle until the flanges rested on the skin. The needle was then removed.

\section{Wire-Guided Technique}

The Minitrach II (Smiths Medical, Hythe, UK) consists of an uncuffed tube with an internal diameter of $4 \mathrm{~mm}$ and an external diameter of $5.4 \mathrm{~mm}, 2$ dilators, a short scalpel, a guidewire, and a short 17-gauge Tuohy needle (Fig. 3). A suction tube and securing tape complete the set. A transverse puncture was made with the guarded blade. The Tuohy needle with a 5-mL syringe attached was advanced until puncture of the airway occurred. Correct placement was confirmed by the ability to aspirate air. The guidewire was then inserted through the Tuohy needle and the needle was removed. The larger dilator was passed through the guidewire into the trachea and then 


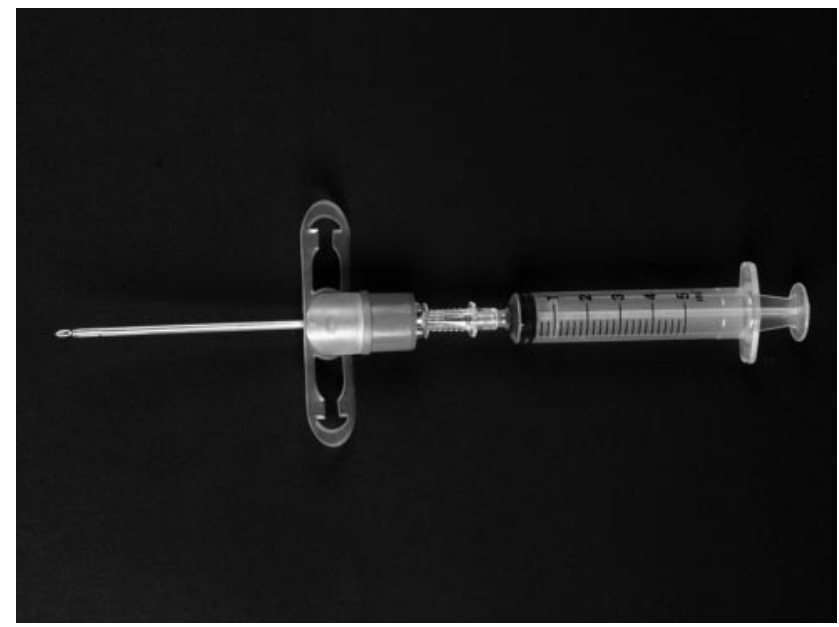

Figure 2. Needle cricothyroidotomy equipment: 13-gauge cricothyroidotomy cannula (VBM Medizintechnik $\mathrm{GmbH}$ ).

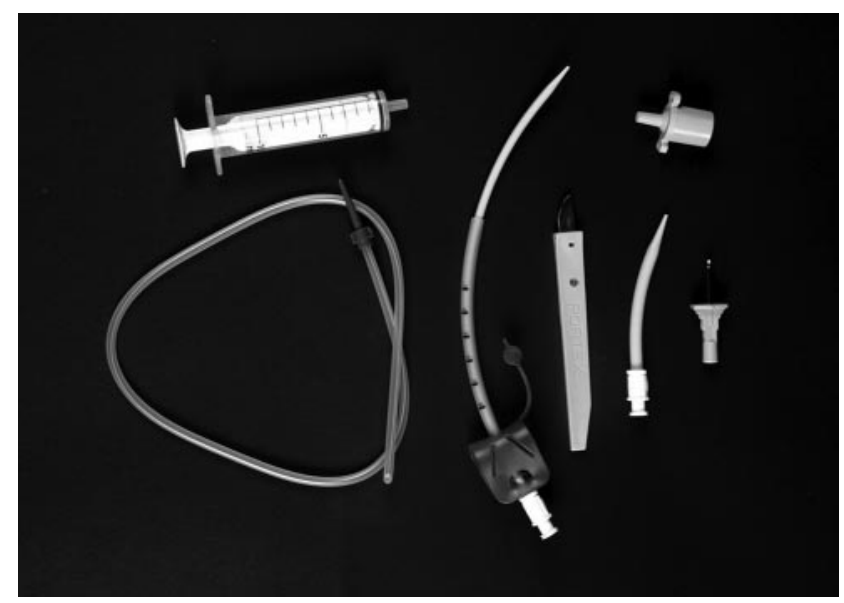

Figure 3. Wire-guided technique equipment: Minitrach II (Smiths Medical).

removed. The Minitrach II, assembled with the smaller dilator, was then passed through the guidewire into the trachea. The guidewire and dilator were removed together, leaving the Minitrach II in place. The 15-mm connecting port was attached.

\section{Surgical Technique}

A 6.0-mm cuffed endotracheal tube (Mallinckrodt ${ }^{\circledR}$, Hazelwood, MO), external diameter $8.2 \mathrm{~mm}$, with a scalpel blade (size 11, disposable) and handle was used (Fig. 4). After identification of the insertion site, a $20-\mathrm{cm}$ horizontal incision was made, cutting through skin and the underlying trachea. Once the tracheal lumen had been reached, the scalpel handle was then inserted horizontally into the incision, rotated $90^{\circ}$, and pushed toward 1 side. This was done to facilitate the subsequent insertion of the endotracheal tube.

\section{Outcomes}

The tracheas were examined for evidence of tissue damage on completion of the device insertion. This was performed by visual inspection of the tracheal

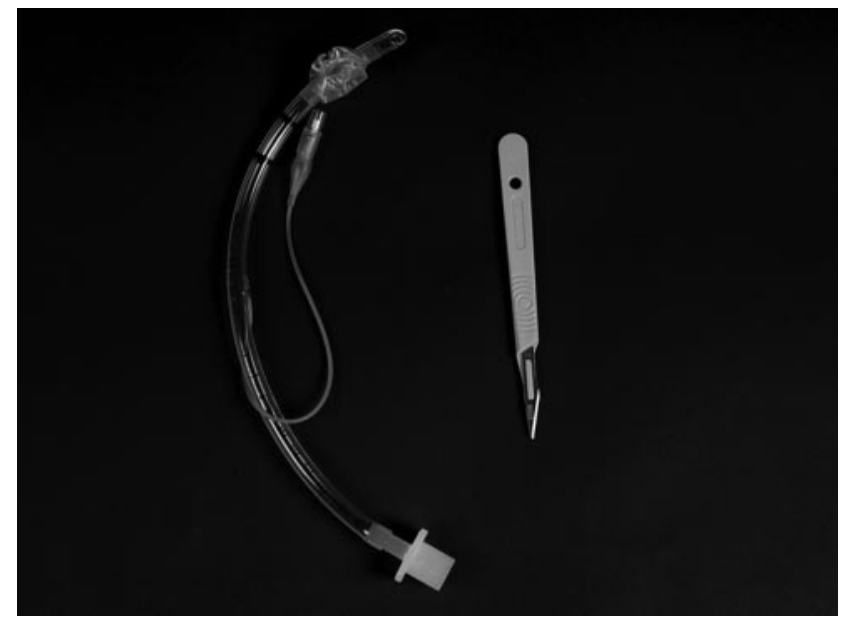

Figure 4. Surgical technique equipment: 6.0-mm cuffed endotracheal tube (Mallinckrodt $\left.{ }^{\circledR}\right)$ with a scalpel blade (size 11, disposable).

specimen and the white cardboard on which the specimen was mounted. Tracheas were bivalved (transected longitudinally along both lateral walls) and inspected further using a magnifying glass $(75-\mathrm{mm}$ diameter, $4 \times$ ) and 1-mm probe. Photographs of obvious damage were taken using a digital single-lens reflex camera (EOS 400D, Canon ${ }^{\circledR}$, Tokyo, Japan) in macro mode.

Tissue injury was categorized as follows:

Superficial-visible to the naked eye, but the tissue probe could not pass into the tissue wall.

Penetrating - the probe could pass partially but not completely through the tissue wall.

Perforating-evidence of damage to mounting board (paper) and/or passage of blunt tissue probe through tissue wall.

Fracture of the tracheal cartilage was determined by inspection with transillumination and palpation.

Maximum tracheal compression during device insertion was determined from video recordings and graded as follows: Grade $0=$ no tracheal wall compression; Grade $1=<50 \%$ compression; and Grade $2=>50 \%$ compression.

Additional data collected included clinical experience of the participants in years and previous attendance at an airway skills course.

\section{Statistical Analysis}

Data were analyzed using Sigma Stat (Version 2.0; Jandel Corporation, San Rafael, CA). Categorical data were analyzed using Fisher's exact test and $\chi^{2}$ testing, with Yates correction as appropriate. Data are presented as numbers and percentages. Significance was considered at a level of $P<0.05$.

\section{RESULTS}

\section{Participants}

Each participant performed 8 procedures. Forty tracheal specimens were used (diameter $17.5 \pm 1.5 \mathrm{~mm}$ ). 


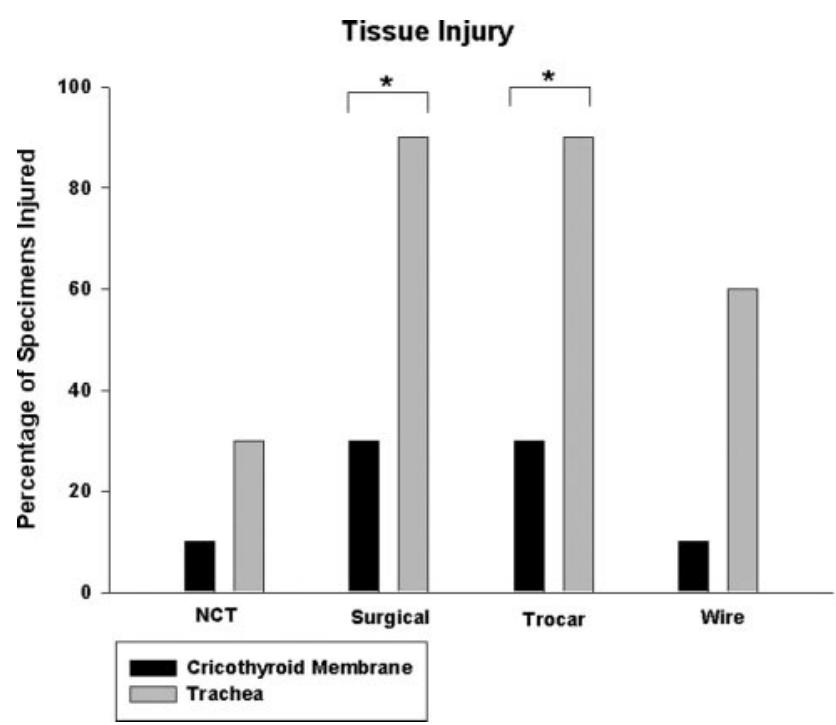

Figure 5. Tissue injury-percentage of specimens with any injury, ${ }^{*} P<0.05$.

\section{Tissue Injury}

Tissue injury was more frequent when the procedure was performed at the tracheal site compared with the CTM in both the TT and surgical technique (ST) $(P=0.02)$ groups but not for the needle cannula (NCT) and wire-guided technique (WGT) groups (Fig. 5). Patterns of injury were different depending on the site of the procedure. Injury was observed in 8 of 40 specimens where the procedure was performed at the CTM and 27 of 40 at the trachea $(P<0.001)$. The rank order for injury at the tracheal site (highest to lowest) was ST $=$ TT $>$ WGT $>$ NCT $(P=0.02$, highest versus lowest), whereas the rank order for injury at the CTM was $\mathrm{ST}=\mathrm{TT}>\mathrm{WGT}=\mathrm{NCT}(P=0.58$, highest versus lowest). Posterior injury was more common with the TT and ST compared with NCT via the tracheal site (Table 1). The rank order for posterior injury at the tracheal site was ST $(9$ of 10) $=$ TT $(9$ of 10) $>$ WGT $(5$ of 10$)>\operatorname{NCT}(2$ of 10$)(P=0.005$, highest versus lowest). At the tracheal site the rank order of injury was $\mathrm{ST}=\mathrm{TT}>$ WGT $>$ NCT $(P<0.057$, highest vs lowest). There was no difference in the incidence of lateral, superficial, or perforating injuries among sites or techniques (Table 1). Fractures were more common where airway access was attempted at the tracheal site than at the CTM (15 of 40 vs 0 of $40, P<0.001$ ) and differed by technique. The rank order of fracture incidence at the tracheal site was ST (6 of 10) $>$ WGT $(5$ of 10$)>$ TT $(4$ of 10$)>$ NCT $(4$ of 10$)(P=0.011$, highest to lowest) (Table 1).

\section{Compression}

Maximum compression of the specimen lumen was more common at the tracheal site than at the CTM for the NCT technique $(P=0.001)$ but not for the other techniques (Table 2). Compression of $>50 \%$ was seen in 10 of 40 specimens at the CTM versus 28 of 40 at the tracheal site $(P<0.001)$ (Table 2$)$. The rank order of compression of $>50 \%$ at both the CTM and tracheal sites was TT $>$ ST $>$ WGT $>$ NCT $(P=0.03, P<0.001$, respectively, highest versus lowest) (Table 2). Posterior airway injury was greatest at the tracheal site in the ST and TT groups in the presence of tracheal compression of $>50 \%$ (Table 3 ).

\section{DISCUSSION}

This study was designed to determine the pattern of airway injuries that occur if transcutaneous airway access is inadvertently performed via the trachea compared with the recommended site, the CTM. In this study, airway injury was most frequently seen when access was attempted at the tracheal site using the TT and ST. Posterior wall tissue injury was seen in $90 \%$ and posterior wall penetration in $60 \%$ of attempts at the tracheal insertion site with each of these approaches, and no injuries were observed at this site in the absence of tracheal compression. At the CTM, the incidence of injury was lower, but posterior wall penetration was still seen using the TT and ST in $20 \%$ and $10 \%$ of specimens, respectively. The lowest incidence of injury was seen with the NCT and WGT at the cricothyroid site, and no posterior wall penetration was observed. Fractures were observed only at the

Table 1. Tissue Injury

\begin{tabular}{|c|c|c|c|c|c|c|c|}
\hline Technique & Site & $\begin{array}{c}\text { Posterior } \\
\text { injury, } N(\%)\end{array}$ & $\begin{array}{l}\text { Lateral wall } \\
\text { injury, } N(\%)\end{array}$ & $\begin{array}{c}\text { Superficial } \\
\text { injury, } N(\%)\end{array}$ & $\begin{array}{l}\text { Penetrating } \\
\text { injury, } N(\%)\end{array}$ & $\begin{array}{l}\text { Perforating } \\
\text { injury, } N(\%)\end{array}$ & $\begin{array}{c}\text { Fracture, } \\
N(\%) \\
\end{array}$ \\
\hline \multirow[t]{2}{*}{ Needle } & $\begin{array}{l}\text { Cricothyroid } \\
\text { membrane }\end{array}$ & $1(10)$ & $0(0)$ & $1(10)$ & $0(0)$ & $0(0)$ & $0(0)$ \\
\hline & Trachea & $2(20)$ & $1(10)$ & $2(20)$ & $1(10)$ & $0(0)$ & $0(0)$ \\
\hline \multirow[t]{2}{*}{ Surgical } & $\begin{array}{l}\text { Cricothyroid } \\
\text { membrane }\end{array}$ & $3(30)$ & $0(0)$ & $1(10)$ & $1(10)$ & $1(10)$ & $0(0)$ \\
\hline & Trachea & $9(90)^{*}+$ & $1(10)$ & $3(30)$ & $6(60)$ & $0(0)$ & $6(60)^{*}+$ \\
\hline \multirow[t]{2}{*}{ Trocar } & $\begin{array}{l}\text { Cricothyroid } \\
\text { membrane }\end{array}$ & $3(30)$ & $0(0)$ & $0(0)$ & $2(20)$ & $1(10)$ & $0(0)$ \\
\hline & Trachea & $9(90)^{*}+$ & $0(0)$ & $0(0)$ & $6(60)$ & $3(30)$ & $4(40)$ \\
\hline \multirow[t]{2}{*}{ Wire guided } & $\begin{array}{l}\text { Cricothyroid } \\
\text { membrane }\end{array}$ & $1(10)$ & $0(0)$ & $1(10)$ & $0(0)$ & $0(0)$ & $0(0)$ \\
\hline & Trachea & $5(50)$ & $1(10)$ & $4(40)$ & $2(20)$ & $0(0)$ & $5(50)^{*}+$ \\
\hline
\end{tabular}

$* P<0.05$ versus cricothyroid membrane using same technique.

$\dagger P<0.05$ versus tracheal site, needle technique. 


\begin{tabular}{|c|c|c|c|c|c|}
\hline Technique & Site & $\begin{array}{c}\text { No compression, } \\
N(\%)\end{array}$ & $\begin{array}{l}\text { Compression } \\
<50 \%, N(\%)\end{array}$ & $\begin{array}{l}\text { Compression } \\
>50 \%, N(\%)\end{array}$ & $\begin{array}{l}\text { Compression } \\
100 \%, N(\%)\end{array}$ \\
\hline \multirow[t]{2}{*}{ Needle } & Cricothyroid membrane & $9(90.0)$ & $1(10.0)$ & $0(0.0)$ & $0(0.0)$ \\
\hline & Trachea & $1(10.0)^{*}$ & $7(70.0)^{*}$ & $2(20.0)$ & $0(0.0)$ \\
\hline \multirow[t]{2}{*}{ Surgical } & Cricothyroid membrane & $1(10.0)$ & $5(50.0)$ & $4(40.0)$ & $1(10.0)$ \\
\hline & Trachea & $1(10.0)$ & $1(10.0)$ & $9(90.0) \dagger$ & $3(30.0)$ \\
\hline \multirow[t]{2}{*}{ Trocar } & Cricothyroid membrane & $0(0.0)$ & $5(50.0)$ & $5(50.0)$ & $1(10.0)$ \\
\hline & Trachea & $0(0.0)$ & $0(0.0)^{*}$ & $10(100.0)^{*}+$ & $1(10.0)$ \\
\hline \multirow[t]{2}{*}{ Wire guided } & Cricothyroid membrane & $0(0.0)$ & $9(90.0)$ & $1(10.0) \dagger$ & $0(0.0)$ \\
\hline & Trachea & $0(0.0)$ & $3(30.0)^{*}$ & $7(70.0)^{*}$ & $0(0.0)$ \\
\hline
\end{tabular}

$N$ (\%): number (percentage) of specimens with lumen compression.

$* P<0.05$ versus cricothyroid membrane using same technique.

$\dagger P<0.05$ versus compression $<50 \%$ using same technique.

Table 3. Posterior Airway Injury and Degree of Lumen Compression

\begin{tabular}{|c|c|c|c|c|c|}
\hline Technique & Site & $\begin{array}{c}\text { No compression, } \\
\qquad N(\%)\end{array}$ & $\begin{array}{l}\text { Compression } \\
<50 \%, N(\%)\end{array}$ & $\begin{array}{l}\text { Compression } \\
>50 \%, N(\%)\end{array}$ & $\begin{array}{l}\text { Compression } \\
100 \%, N(\%)\end{array}$ \\
\hline \multirow[t]{2}{*}{ Needle } & Cricothyroid membrane & $1(10.0)$ & $0(0.0)$ & $0(0.0)$ & $0(0.0)$ \\
\hline & Trachea & $1(10.0)$ & $2(20.0)$ & $2(20.0)$ & $0(0.0)$ \\
\hline \multirow{2}{*}{ Surgical } & Cricothyroid membrane & $0(0.0)$ & $1(10.0)$ & $1(10.0)$ & $0(0.0)$ \\
\hline & Trachea & $0(0.0)$ & $1(10.0)$ & $8(80.0)^{*}$ & $3(30.0)$ \\
\hline \multirow[t]{2}{*}{ Trocar } & Cricothyroid membrane & $0(0.0)$ & $1(10.0)$ & $2(20.0)$ & $1(10.0)$ \\
\hline & Trachea & $0(0.0)$ & $0(0.0)$ & $10(100.0)^{*}$ & $1(10.0)$ \\
\hline \multirow{2}{*}{ Wire guided } & Cricothyroid membrane & $0(0.0)$ & $1(10.0)$ & $0(10.0)$ & $0(0.0)$ \\
\hline & Trachea & $0(0.0)$ & $2(20.0)$ & $4(40.0)$ & $0(0.0)$ \\
\hline
\end{tabular}

$N$ (\%): number (percentage) of specimens with posterior injury.

$* P<0.05$ versus compression $<50 \%$ using same technique.

tracheal site and were observed with all techniques except the NCT.

Airway injury and compression were the primary and only outcome measures of our study. We did not assess other important measures of efficacy such as time to effective ventilation. Clearly, not all of the injuries assessed are of equal clinical importance. Superficial nonpenetrating injuries are likely to cause minimal morbidity, whereas deeper, penetrating injury is more likely to cause the more serious complications that have been previously described, namely, vascular injury, pneumothorax, subcutaneous emphysema, vocal cord injury, laryngeal cartilage fracture, esophageal/mediastinal perforation, and subsequent mediastinitis and tracheoesophageal fistula. ${ }^{9}$

\section{Comparison of Data from This Study with Previous Studies}

Although the anatomy of the CTM has been well described, relatively little attention has been given to the ability of physicians to accurately locate it when necessary. Recognized risk factors for difficult intubation and mask ventilation include obesity, a beard, and a short, thick neck. ${ }^{10}$ Patients who need emergency airway access may be wearing hard collars and are agitated because of hypoxia. Thus, patients at risk of failure of conventional airway management are conceivably also at risk of misidentification of the CTM. There is evidence, even under controlled laboratory conditions, to suggest that attempts to access the airway via the CTM are frequently unsuccessful and anatomically inaccurate.

In a large cadaveric study in which cricothyroidotomy was the planned procedure, intensive care physicians successfully placed the airway inside the trachea in only $70 \%$ of attempts using a conventional surgical technique and $60 \%$ using the Seldinger technique. ${ }^{5}$ Misplacements were paratracheal, esophageal, and subcutaneous, and injuries occurred in 15\% and $10 \%$, respectively. The puncture of thyroid vessels in that study suggests that many of the insertions were below the CTM.

In a manikin study of airway access via the CTM, malpositioning of devices in the posterior tracheal wall, insertion below the CTM, and insertion through the thyroid cartilage all occurred. ${ }^{11}$ Vadodaria et al. ${ }^{12}$ demonstrated posterior tracheal wall injuries in 20\% of all attempts with Quicktrach, Melker, Patil's Airway, and transtracheal airway catheter sets in a human patient simulator.

In a porcine airway model similar to ours, Fikkers et al. ${ }^{13}$ demonstrated posterior tracheal wall injuries in $20 \%$ of wire-guided cricothyroidotomies compared with none with a cannula-over-needle technique. Fifty percent of these injuries were tracheal perforations. Additionally, $5 \%$ of devices were misplaced with each technique. We demonstrated airway injury regardless of which technique was chosen, even at the anatomically correct site (the CTM). This suggests that airway 


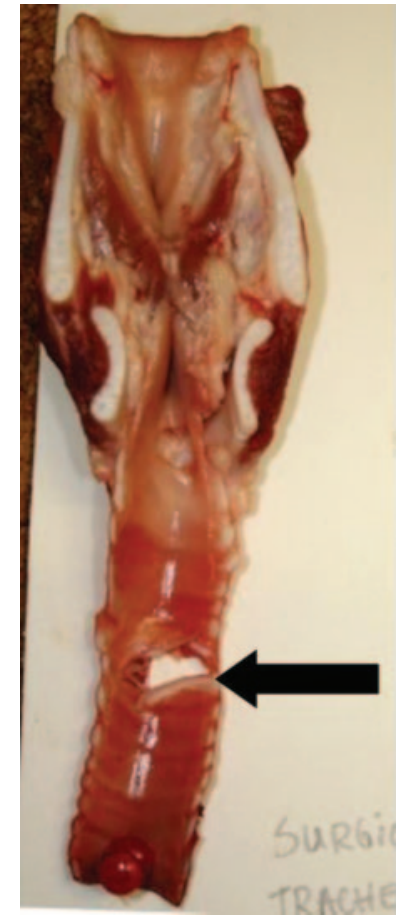

Figure 6. Severe posterior tracheal wall injury seen after tracheal access with the surgical technique.

injury is not completely unavoidable, even under laboratory conditions.

\section{Efficacy and Safety}

The devices in our study that are most likely to provide both effective oxygenation and ventilation are the wider external bore cuffed tubes of the Quicktrach II and the 6.0 endotracheal tube inserted with the scalpel. However, these were associated with the high incidence of injury. This is consistent with observations by Abbrecht et al. ${ }^{14}$ that devices with larger diameters required greater forces for insertion and were associated with higher complication rates. Injuries occurring with use of these devices are not, however, caused exclusively by the tubes themselves but by the cutting edges of the devices used to insert them (Fig. 6). Airway access with a surgical technique produced an incidence of airway injury comparable with that of the trocar technique at both airway access sites. This may reflect the participating anesthesiologists' relative lack of familiarity with the surgical technique. Techniques using thin-bore needles for insertion (13-gauge cannula and 17-gauge Tuohy) were associated with fewer injuries and presumably required less insertion force. However, the 13-gauge cannula is not recommended for oxygenation in airway obstruction, because of the risk of barotrauma and it requires specialized equipment to be effective. ${ }^{15-17}$ Anesthesiologists are familiar with wire-guided techniques but may be slow performing them, and some commercial kits use uncuffed tubes, which limit effective ventilation because of proximal leakage. ${ }^{16,18}$

\section{Limitations of This Study}

The airway model we chose in this study was constructed from excised porcine tracheas with intact laryngeal structures (including CTMs) covered with synthetic skin. The porcine trachea most accurately approximates the dimensions of the female adult airway, ${ }^{7}$ and because the specimens were freshly prepared, we could estimate compression and airway injury accurately (compared with relatively inflexible tissues in frozen or formalin-preserved specimens). However, because there is no mandible or underlying pretracheal tissue, this model is not anatomically correct; consequently, airway access may have been easier in our model. Additionally, laboratory models cannot convey the sense of urgency and difficulty encountered in the clinical situation, where difficult patient anatomy, patient movement, and bleeding are present. Finally, our participants were experienced in the use of the various devices in an anatomically correct manikin airway (having had at least 5 previous attempts with each technique), and so were not comparable to first-time, inexperienced users or to users whose cricothyroidotomy experience was not recent.

\section{Implications for Anesthetic Practice}

The results of our study in an airway model without laryngeal pathology provide further supportive evidence for the recommendation that emergency airway access should be preferentially performed at the CTM. In addition to regular training with recommended techniques, emphasis should be placed on correct anatomic localization of the CTM to attempt to avoid malplacement, which is associated with increased complication rates. In the case of a potentially difficult airway, there may be merit in identifying and marking the CTM before any attempted intubation.

\section{REFERENCES}

1. Peterson GN, Domino KB, Caplan RA, Posner KL, Lee LA, Cheney FW. Management of the difficult airway: a closed claims analysis. Anesthesiology 2005;103:33-9

2. Fortune JB, Judkins DG, Scanzaroli D, McLeod KB, Johnson SB. Efficacy of prehospital surgical cricothyrotomy in trauma patients. J Trauma 1997;42:832-6

3. Clancy MJ. A study of the performance of cricothyroidotomy on cadavers using the Minitrach II. Arch Emerg Med 1989;6:143-5

4. Schaumann N, Lorenz V, Schellongowski P, Staudinger T, Locker GJ, Burgmann H, Pikula B, Hofbauer R, Schuster E, Frass M. Evaluation of Seldinger technique emergency cricothyroidotomy versus standard surgical cricothyroidotomy in 200 cadavers. Anesthesiology 2005;102:7-11

5. Eisenburger P, Laczika K, List M, Wilfing A, Losert H, Hofbauer R, Burgmann H, Bankl H, Pikula B, Benumof JL, Frass M. Comparison of conventional surgical versus Seldinger technique emergency cricothyrotomy performed by inexperienced clinicians. Anesthesiology 2000;92:687-90

6. Randell T, Kalli I, Lindgren L. Minitracheotomy: complications and follow-up with fibreoptic tracheoscopy. Anaesthesia 1990;45: 875-9

7. Breatnach E, Abbott GC, Fraser RG. Dimensions of the normal human trachea. AJR Am J Roentgenol 1984;142:903-6

8. Bennett JD, Guha SC, Sankar AB. Cricothyrotomy: the anatomical basis. J R Coll Surg Edinb 1996;41:57-60

9. Boon JM, Abrahams PH, Meiring JH, Welch T. Cricothyroidotomy: a clinical anatomy review. Clin Anat 2004;17:478-86 
10. Wilson ME, Spiegelhalter D, Robertson JA, Lesser P. Predicting difficult intubation. Br J Anaesth 1988;61:211-6

11. Assmann NM, Wong DT, Morales E. A comparison of a new indicator-guided with a conventional wire-guided percutaneous cricothyroidotomy device in mannequins. Anesth Analg 2007; 105:148-54

12. Vadodaria BS, Gandhi SD, McIndoe AK. Comparison of four different emergency airway access equipment sets on a human patient simulator. Anaesthesia 2004;59:73-9

13. Fikkers BG, van Vugt $S$, van der Hoeven JG, van den Hoogen FJ, Marres HA. Emergency cricothyrotomy: a randomised crossover trial comparing the wire-guided and catheter-over-needle techniques. Anaesthesia 2004;59:1008-11
14. Abbrecht PH, Kyle RR, Reams WH, Brunette J. Insertion forces and risk of complications during cricothyroid cannulation. J Emerg Med 1992;10:417-26

15. Dworkin R, Benumof JL, Benumof R, Karagianes TG. The effective tracheal diameter that causes air trapping during jet ventilation. J Cardiothorac Anesth 1990;4:731-6

16. Craven RM, Vanner RG. Ventilation of a model lung using various cricothyrotomy devices. Anaesthesia 2004;59:595-9

17. Scrase I, Woollard M. Needle vs surgical cricothyroidotomy: a short cut to effective ventilation. Anaesthesia 2006;61:962-74

18. Dimitriadis JC, Paoloni R. Emergency cricothyroidotomy: a randomised crossover study of four methods. Anaesthesia 2008; 63:1204-8 